and match products from different vendors. Each classroom contains one "teacher's workstation" and four "student workstations." Each student workstation serves a small group of 3-5 students and reflects the teachers' desire to support a cooperative learning method of instruction. The workstations are interconnected by local area networks (LANs) and share a laser printer that supports both the Macintosh and PC computers. The teacher's workstations include an overhead projector with an LCD display panel for class instruction and demonstrations, plus a modem to permit connection to Minitel (the French on-line computer service), Prodigy, and the Internet. Since video services are an important part of the "operational con-

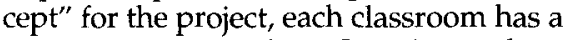
27-in. television and a VCR. The teachers share access to a camcorder.

\section{Promising Results}

Results, to date, have been encouraging. We began in spring 1993 with approximately 150 ninth through twelfth grade students in 10 classes. Now, about a year and a half later, the technology has already changed the teachers' instructional approach.

Although there is little hard data to evaluate the project's overall effectiveness, the anecdotal evidence is very positive. Technology has become a "hook" that attracts students. Attendance in the technology-enhanced French and social studies classes has increased. This is significant in a school where 20 percent of the students are absent on a normal day and where 40 percent of the students drop out before graduating. Students
The Education Exchange highlights the experiences of scientists and engineers with local schools, along with helpful hints and resources. If you would like to share your own involvement in science education, contact: Finley Shapiro, Department of Electrical and Computer Engineering, Drexel University, Philadelphia, PA 19104, U.S.A. Phone (215) 895-6749; fax (215) 895-1695; email: shapiro@ece.drexel.edu.

want to stay after school and come to school on Saturdays to use the computers. Enrollment in the French classes increased by more than 50 percent in fall 1993, the first new academic year after the technology was installed. These results suggest that the students are ready, willing, and eager to use technology in their classrooms. All they and their teachers need are support and encouragement.

\section{Looking Ahead}

Using our results from Springfield as a model, we have begun working at the state and national levels to help apply modern technology in $\mathrm{K}-12$ education. Two of the things we think are important in promoting the large-scale use of educational technology are:

- A family of technical specifications and standards (not instructional content standards) for educational technology products such as software and multimedia materials. These standards would make it easier for schools to select, install, use, and maintain such products. They could also create a common framework for the development of new products which, in turn, could stimulate industry to invest in developing such products at prices that schools can afford.

- Regional consortia of school systems to promote the use of educational technology, share in the development of new applications, and promote the reuse of products and efforts that have proven to be effective in individual schools or school systems.

\section{BARRY HOROWITZ and NELSON BOLEN}

Barry M. Horowitz is president and CEO of the MITRE Corporation, an independent notfor-profit systems engineering firm engaged in scientific and technical activities for the public benefit. Horowitz has been active in promoting business support to education and is the current chairman of the Education Task Force of the Massachusetts Business Roundtable. His address is The Mitre Corporation, 202 Burlington Road, Bedford, MA 01730-1420; phone: (703) 883-6211; fax: (703) 883-5468; e-mail:bmh@mbunix.mitre.org.

Nelson E. Bolen is an associate technical director at the MITRE Corporation and has been actively involved in the corporation's work in education and training. His address is The Mitre Corporation, 202 Burlington Road, Bedford, MA 01730-1420; phone: (617) 271-3101; fax: (617) 271-2738; e-mail: neb@mbunix.mitre.org.

To receive additional information on how you can get involved in enhancing $\mathrm{K}-12$ science education, circle number 120 on the Reader Service Card.

\title{
Lines of Communication
}

Cables used to transmit telephone calls, telegraph messages, or pictures (e.g., closed-circuit television) are designed for low voltages and small currents. They contain one or more current-carrying conductors, isolated by a surrounding insulating material.

The telegraph, invented in the 1830 s, was the first system designed to use electrical impulses to transmit messages. As the use of telegraph cables spread across the United States-usually lengths of bare, hard-drawn copper wire supported on insulators are mounted on poles-an entire wire and cable industry was developed to support the undertaking. Within thirty years, most major American cities were connected by telegraph lines, and messages were transmitted over long distances in minutes.

Many attempts were made to lay down undersea telegraph cables, but insulation materials suitable for enduring immersion in sea water could not be found. Tarred rope, split rattan, india rubber, and impregnated cotton were all found unsuitable. Finally, in 1848, Ernst Werner von Siemens used the gum, gutta-percha, from a Malayan tree to successfully insulate a line transmitting signals to detonate mines in Kiel Harbor in Germany.

Two years later, on 28 August 1850, the tug Goliath laid the first submarine telegraph cable between Dover and Calais: 25 miles of a single conductor surrounded by gutta-percha insulation. Though this cable soon failed, its English creators-Jacob and John W. Brett-succeeded in 1851 with a second cable. This cable, consisting of four copper wires and gutta-percha insulation, remained in use until 1875. 
Gutta-percha proved to have such fine mechanical and electrical properties that it remained the most widely used insulator for undersea cables for the next 70 years, until improved substitutes such as deproteinized rubber and polyethylene were developed in the late 1920s.

The next goal was to connect North America with Europe, but this proved more difficult. The engineer Charles Bright undertook the task to link Ireland and Newfoundland. He and his coworkers failed in their attempt in 1857 and again in 1858. A second attempt in 1858 was successful, but only from August 5 to September 1, during which time Queen Victoria transmitted a message to President James Buchanan, and received his reply. On August 20, the first news message-announcing a collision of two ships off Newfoundland-was transmitted over the cable. Several days after Bright secured the cable in Ireland, he was knighted. Another attempt was made in 1865, which was unsuccessful.

The following year the first successful transatlantic telegraph cable was laid from Valentia, Ireland to Heart's Content, Newfoundland in only two weeks, again with Charles Bright as supervising engineer. The cable-laying ship, the Great Eastern, was the largest ship in the world at the time. It laid down $3432 \mathrm{~km}(1852$ nautical miles) of cable from a drum at its stern, at a rate of about $11 \mathrm{~km}$ (6 nautical miles) per hour.

The submarine cable was 1.1 inches (2.8 $\mathrm{cm}$ ) in diameter and consisted of a sevenstrand copper conductor, four layers of gutta-percha insulation, a wrapping of tarred hemp, and an armor of ten steel wires wrapped in impregnated hemp. During the whole length of the voyage, the Great Eastern continuously transmitted a signal through the cable back to Ireland.

When the transatlantic cable was successfully connected in Newfoundland, the first message transmitted said, simply, "All right." Within the next few days, Queen Victoria sent a message to President Andrew Johnson, and he replied, both at a rate of about eight words per minute. This cable remained in use for six years, during which time the failed 1865 cable was repaired, providing two functioning transatlantic cables.

By the turn of the century, a dozen telegraph cables crossed the Atlantic; several others crossed the Pacific. One laid in 1902 stretched from Vancouver Island in Canada to Brisbane, Australia. The following year President Theodore Roosevelt participated in an experiment to send the first around-the-world tele- graph message. It was sent completely around the Earth in nine minutes.

In 1876, Alexander Graham Bell invented the telephone, creating the need for improved cables to be used for the transmission of voice communications. Initially, telephone lines used bare wires and insulators mounted on poles, like telegraph cables. This soon proved unsatisfactory because transmission of speech over relatively long distances led to a loss of signal strength and distortion, garbling the speech signals at the receiving end.

\section{Gutta-percha remained the most widely used insulator for undersea cables for 70 years.}

By 1890 , following the success of submarine telegraph cables, possibilities for undersea telephone cables began to be investigated. The Danish government laid a cable in 1902 that provided communication over only short distances in shallow water before the voice signal deteriorated.

The electrical properties of the cable material then became an issue. The mathematical work of Oliver Heaviside in England from 1885 to 1887 stressed capacitance and inductance in cables. In 1899 in America, Michael I. Pupin added induction coils to telephone cables in order to deliver a strong and clear voice transmission. The first fully functional telephone route overland across America was opened in 1915.

Around 1920, while working for Western Electric and later with the Bell Telephone Laboratories, Gustav W. Elmen discovered permalloys (iron-nickel and iron-cobalt alloys), which were found to be very useful materials for communication cables. Elmen's permalloys were used to make deep-sea cables with large message-carrying capacity.

With the development of amplifiers, more submarine telephone cables were tried, using repeaters to boost the voice signal along the great length of the cable. (A repeater amplifier is inserted into the circuit to maintain signal strength and fidelity.) The first successful submarine cable with repeater amplifiers stretched from Wales to the Isle of Man in 1943.

These cables were encased in a hollow, flexible steel tube that could withstand the great pressures at ocean depths; unfortunately, the steel sheath had only enough space to place repeater amplifiers in one direction. To remedy this, a parallel cable was laid in the opposite direction across the entire cable path.

In a joint venture by British, Canadian, and American organizations, the first transatlantic telephone cable was completed in 1956; it connected Clarenville, Newfoundland with Oban, Scotland. In similar efforts, parallel submarine cables were laid from San Francisco to Honolulu in 1957, and another pair from the U.S. to France in 1959.

The concept of using orbiting satellites as communications repeaters in place of physical cables linking distant parts of the world was first proposed by science fiction writer Arthur C. Clarke in the October 1945 issue of Wireless World. After several experiments conducted by NASA and the U.S. Army, the TELSTAR and RELAY satellites were launched, each having a capacity to carry several hundred voice channels or one television channel. The Communications Satellite Corporation (COMSAT) was incorporated on 1 February 1963 as a private U.S. company to establish a commercial communications satellite system. The following year the International Telecommunications Satellite Consortium (INTELSAT) was formed with 12 countries (this number had increased to 110 members by 1980). Intelsat I (also called EARLY BIRD) was launched in 1965, providing 240 telephone circuits across the North Atlantic. To date, the largest-capacity satellite launched thus far is Comstar, leased by Comsat General Corporation to American Telephone and Telegraph (AT\&T). Its capacity is 18,000 two-way telephone circuits, or 24 television channels. Far more efficient, satellite communications have supplanted many long-distance communications cables.

Locally, telecommunications systems are replacing their older metallic cables with fiberoptic strands, which are able to carry more information in less space (mentioned in the Historical Note in Issue XV, No. 11 of the MRS BULLETIN).

It seems difficult to believe that only a few decades ago no communications cables had crossed the Pacific Ocean or linked many out-of-the-way places.

KEVIN J. ANDERSON

For FurTher ReAding: Bern Dibner, The Atlantic Cable (Norwalk, CT, 1957); C.C. Barnes, Electric Cables (New York, 1964); and for particular historical interest, H.D. Wilkinson, Submarine Cable Laying and Repairing (New York, second edition published in 1908). 